\title{
Amy Louise Maynard: A Scene in Sequence: Australian Comics Production as a Creative Industry 1975-2017
}

\author{
University of Adelaide, Adelaide, Australia, 1975-2017, 2017, 264 pp., \\ Thesis, The University of Adelaide, Adelaide, South Australia, 5005 \\ Australia
}

\section{Paige Spence ${ }^{1}$}

Published online: 3 July 2020

(c) Springer Science+Business Media, LLC, part of Springer Nature 2020

Discussion about the production and distribution of comics by Australian creators is a rare sight in any form, especially within an academic context. This remains the case despite a move by the general population towards celebrating diverse forms of pop culture and the gradual rise of comics studies as a legitimate field of research over the last two decades. The absence of such discussion may lead one to question whether Australian works of the medium actually exist in any substantial number-even within the country, local comics stores are stacked with international imports and any film adaption of a comic book is predictably tied to foreign origins. However, despite this lack of prominence in the public and academic eye, the production of comics is hardly absent in the country; Australian stakeholders have contributed to the medium's modern history since the 1970s. In Amy Louise Maynard's doctoral thesis A Scene in Sequence: Australian Comics Production as a Creative Industry 1975-2017, this little-explored network of comics creators, producers, editors, sellers, cultural intermediaries and the scene they create is provided significant academic attention for the first time in a decade. By framing this network as a creative industry, Maynard provides an extensive examination of historical and contemporary Australian comics production.

A Scene in Sequence spans nine chapters, which together tell an overarching socioeconomic narrative about the industry's past and present. The initial three chapters serve as an introduction to this narrative, providing the reader with the relevant historical, geographical and methodological background. The historical recount is particularly interesting, revealing the medium's surprisingly distant origins in the early 1900s and the issues it has faced in various periods until the present day. The remainder of the chapters explore the modern circumstances of the funding,

Paige Spence

paige.spence@student.curtin.edu.au

1 Perth, Australia 
production, distribution, circulation and community of the industry, concluding with an exploration of the portrayal of comics by the mainstream media. The data that forms these chapters was gathered by Maynard primarily through an ethnography, which she conducted through interviewing industry stakeholders and partaking in their spaces, from conventions to comics meets. Beneath her technical description and analysis sits a sense of the warmth Maynard fostered throughout her work for these stakeholders and their craft, as well as a sympathy for the economic difficulties they face in a country that offers their work so little attention.

Although Maynard has clearly gained an affection for Australian comics and their stakeholders throughout her work, she admits to having lacked a familiarity with the medium before her research began. Perhaps that absence of initial familiarity is why the thesis so clearly describes element of comics production-never is a term brushed over that an outsider to the comics scene might be unfamiliar with. The result of such attention to these details throughout the piece is a broad (but not deep) introductory exploration of comics production in Australia. This lack of depth is purposeful. The comics studies field is not only young but still preoccupied with literary analysis, and occasionally the historical cataloguing and educational application, of comics. Research into the production and publication side of the medium is uncommon and near unheard of in Australia, aside from some notable works like those by Kevin Patrick. A Scene in Sequence, therefore, works to lay the contemporary groundwork that is absent in the field.

Unfortunately, one problem with any description of the contemporary is how quickly it becomes outdated, especially with regards to an industry as volatile as comics production. Only three years have passed since Maynard completed this thesis and yet countless changes have occurred; publishing houses discussed have closed, new creators have taken the stage, old creators have moved to different platforms, certain conventions have started up or ended permanently and digital methods of comics publishing have continued to evolve. It would also be remiss to not at least question the effect of COVID-19 restrictions on the convention cycle that its many creators rely on. These changes are no fault of Maynard's and the thesis is still a valuable resource for modern times, but it is something to keep in mind while reading.

Other minor criticisms include the disappointment that the thesis cannot dive deeper into some issues, its lack of contacts from Western Australia (despite one of the only Australian comics houses being located there) and the absence of some historical inclusions such as the comics crash of the 1990s. Despite these small issues, the thesis overall cannot be faulted for the information it provides and the work it does to bring together a large amount of knowledge about the Australian comics industry into one place. A Scene in Sequence is a fine starting place for anybody unfamiliar with the Australian comics industry or for those interested in researching it. 